\title{
O papel da ficha de avaliação e da escuta no ensino do gênero seminário
}

\author{
The role of the evaluation form and of listening in the \\ teaching of oral presentation
}

\section{El papel del registro de evaluación y de la escucha en la enseñanza del género seminario}

\author{
Lília Santos Abreu-Tardelli ${ }^{1}$ \\ Kelli Mileni Voltero ${ }^{2}$
}

\begin{abstract}
RESUMO: O artigo parte de uma proposta de ficha de avaliação do seminário oral que visa à formação docente e discente na universidade. A ficha é utilizada em um curso de graduação em Letras para avaliar o gênero seminário em que os discentes apresentam o resultado de um tema selecionado e pesquisado. $O$ objetivo deste artigo é discutir esse dispositivo didático tendo em vista a validade desse instrumento como norteador das futuras ações discentes e docentes, assim como a relevância do papel da escuta durante o seminário. A proposta visa contribuir, de forma mais ampla, para a reflexão sobre o ensino de gêneros orais no espaço acadêmico/escolar, mais especificamente da apresentação oral ou seminário, assim como para a importância de se considerar a avaliação do ouvinte de forma geral (e não apenas do professor).
\end{abstract}

PALAVRAS-CHAVE: Ensino do oral. Seminário. Ficha de avaliação. A escuta. Formação docente inicial.

\footnotetext{
${ }^{1}$ Doutora e Mestra em Linguística Aplicada e Estudos da Linguagem pela PUC-SP e professora da Universidade Estadual Paulista (UNESP), Campus de São José do Rio Preto. lilia.abreutardelli@unesp.br

2 Mestra em Estudos Linguísticos pela Universidade Estadual Paulista (UNESP). Atualmente, cursa doutorado no Programa de Pós-graduação em Estudos Linguísticos na UNESP.

kelli_mileni@hotmail.com
} 
ABSTRACT: The starting point of this article is a proposal of an evaluation form of oral presentations aiming at the development/education of language students (and teachers-tobe) at the university. The evaluation form is used in a Portuguese undergraduate course in order to evaluate students' oral presentations of a topic which was chosen and researched by them. The aim of this article is to discuss this didactic tool as a guide for students as undergraduates and as teachers-to-be, as well as to discuss the relevance of the role of listening during oral presentations. Our purpose is to contribute to the reflection on the teaching of oral genres in academic contexts, more specifically the teaching of oral presentation, as well as the importance of considering the evaluation of the listener in general (and not just the professor's).

KEY WORDS: Teaching of oral. Oral presentation. Evaluation form. Listening. Pre-service teacher training.

RESUMEN: El artículo parte de una propuesta de registro de evaluación del seminario oral que objetiva la formación docente y discente en la Universidad. Se utiliza el registro en una carrera de Letras, en una Universidad de São Paulo, Brasil, a fin de evaluar el género seminario en el que los estudiantes presentan el resultado de un tema seleccionado e investigado. De esta manera, se discute ese dispositivo didáctico considerando la validez de ese instrumento como un guion de las futuras acciones desarrolladas por los docentes y alumnos, así como el papel que desempeña la escucha durante el seminario. La propuesta aspira a contribuir de forma aún más amplia para la reflexión acerca de la enseñanza de géneros orales en el ámbito académico/escolar, específicamente de la presentación oral o seminario, y asimismo para la importancia de considerarse la evaluación del oyente de forma general (y no sólo la del docente).

PALABRAS CLAVE: Enseñanza de la oralidad. Seminario. Registro de evaluación. La escucha. Formación docente inicial.

\section{Introdução}

A importância crescente que se tem dado ao ensino dos gêneros orais nas pesquisas e nos documentos oficiais brasileiros coloca em evidência, no universo educacional e acadêmico, um tema que, nos debates filosóficos e no mundo do trabalho, já é de longa data: as práticas sociais em que se destaca a importância do oral. Obras como Como ouvir de Plutarco (2003) (século I), Sobre a Conversação, de André Morellet (2002) (século XVIII) , Como vencer um debate sem precisar ter razão, de Schopenhauer (2003) (século XIX) são alguns dos clássicos que destacam a importância do oral nas práticas sociais e de persuasão, debatendo desde as "boas 
práticas sociais" até esquemas argumentativos enganosos que os maus filósofos utilizavam para persuadir o público ou ainda as estratégias que um bom ouvinte pode detectar na fala de quem ouve para não se deixar enganar. Essas obras são verdadeiros tratados que ainda hoje nos ensinam comportamentos, estratégias e argumentos que devemos/podemos ter diante de uma plateia ou interlocutor nem sempre benevolente com/para quem fala.

Na linguística, recuperou-se recentemente a obra de Lev Jakubinski, Sobre a fala dialogal (KAJUBINSKI, 2015), e sua contribuição para a teoria do diálogo na linguística russa e sua influência no pensamento de Voloshinov (IVANOVA, 2015).

No mundo do trabalho, para se suprir a deficiência de oratória e interlocução dos profissionais, encontram-se cada vez mais títulos, cursos ou sites destinados a dicas de "como falar bem" diante de um auditório, em uma entrevista de emprego, em uma apresentação para empresa etc., tais como $A$ arte de argumentar (ABREU, 2001), Como falar corretamente e sem inibições (POLITO, 1998), Como Falar em Público e Influenciar Pessoas no Mundo dos Negócios (CARNEGIE, 1996), Como conquistar falando (MARQUES, 1980), dentre outros.

A prática escolar de trabalho com o oral deu-se durante muito tempo com apresentações de "seminários", gênero muito conhecido pelos alunos, geralmente utilizado como formas de avaliação de conteúdo nas mais diversas disciplinas escolares, sem um ensino formalizado. A obra de Mattoso Câmara Junior (1961) intitulada Manual de Expressão Oral e Escrita merece nossa atenção como precursora, no Brasil, de uma sistematização do plano da exposição oral assim como da importância do auditório para um expositor. Três décadas depois, no final dos anos 90, inserida em um contexto educacional norteado pelos Parâmetros Curriculares Nacionais (BRASIL, 1998, 2000), a organização da obra Gêneros orais e escritos na escola (SCHNEUWLY; DOLZ, 2004), encontrou terreno fértil para a inserção e sistematização do ensino do oral. Nessa obra, o oral nos foi apresentado 
na forma de sequências didáticas ${ }^{3}$, inserida no quadro teórico-metodológico do interacionismo sociodiscursivo e, desde então, outros pesquisadores têm se dedicado à questão do ensino do oral no ensino brasileiro, ligados à mesma vertente (BARRICELLI，2015; BAUMGÄRTNER，2015; COSTA-HÜBES; SWIDERSKI，2015; DOLZ; BUENO, 2015; DOLZ; MESSIAS, 2015; FERRAZ; GONÇALVEZ, 2015; LEURQUIN, 2015; LOUSADA; ROCHA; GUIMARÃES-SANTOS, 2015; NASCIMENTO, 2015; SOUZA; CRISTOVÃO, 2015).

Esse interesse considerável de pesquisas sobre o oral, assim como a inclusão do oral e/ou oralidade nos documentos oficiais, fez com que este objeto adentrasse nos materiais didáticos de língua portuguesa da educação básica, apesar de ainda estar ausente nos manuais normativos de produção textual, voltados ao ensino superior.

O presente artigo vem aumentar o coro de vozes em torno do ensino do oral, apresentando o que, no trabalho de sequências didáticas na perspectiva do interacionismo sociodiscursivo, é chamado de ficha de (auto-)avaliação do trabalho realizado pelo aluno. Para isso, partiremos de uma ficha utilizada em um curso de graduação da Universidade Estadual Paulista, para avaliar o gênero seminário em que os discentes devem apresentar um tema pesquisado, após o trabalho desse gênero em uma sequência didática de aproximadamente seis horas (três aulas) 4 . Com isso, pretendemos discutir esse dispositivo didático que defendemos ser necessário ao ensino do oral. Para que essa discussão possa ocorrer, faremos uma síntese do que é abordado sobre essa temática nos documentos oficiais norteadores do ensino, nos manuais de normas acadêmicas e em pesquisas já realizadas. Em relação aos manuais e às pesquisas, focaremos nas que se voltam ao gênero

\footnotetext{
${ }^{3} \mathrm{~A}$ sequência didática (SD) "é um conjunto de atividades escolares organizadas, de maneira sistemática, em torno de um gênero textual oral ou escrito", (DOLZ; NOVERRAZ; SCHNEUWLY, 2004, p. 97). O objetivo da SD é auxiliar o aluno a dominar um gênero textual, seja ele, oral ou escrito.

${ }^{4} \mathrm{~A}$ ficha de (auto-)avaliação e parte da sequência didática são apresentadas posteriormente nos: quadro 1 e quadro 2.
} 
seminário. A partir desse panorama, objetivamos ampliar a discussão sobre o ensino desse gênero, complementando as demais pesquisas já realizadas e apontando pontos a serem aprofundados, mais especificamente, em relação a dois aspectos: a necessidade de a escuta ser trabalhada juntamente com a fala no trabalho com o seminário (e com outros gêneros orais) e da utilização da ficha de avaliação como instrumento norteador do ensino e da aprendizagem.

\section{0 ensino do oral norteado pelos documentos oficiais: o viés da escuta}

Apresentamos uma síntese sobre como o ensino do oral é trazido por alguns documentos que regem o contexto educacional brasileiro, primeiramente, nos Parâmetros Curriculares Nacionais de língua portuguesa (PCN), no Currículo do Estado de São Paulo de Língua Portuguesa e na Base Nacional Comum Curricular de Língua Portuguesa $(B N C C)^{5}$. Essa ordem de apresentação segue as datas das publicações dos referidos documentos, do mais antigo para o mais recente, possibilitando que possamos verificar a importância dada ao ensino do oral e, mais especificamente, ao papel da escuta, pelos documentos oficiais nos últimos vinte anos, uma vez que são documentos que norteiam, há muito tempo ou mais recentemente, o ensino no país e no estado de São Paulo.

Segundo proposto nos PCN (BRASIL, 1998), a oralidade e os gêneros orais, principalmente os que circulam em situações formais de uso, devem ser trabalhados no contexto escolar, para os alunos serem capazes de "responder a diferentes exigências de fala e de adequação às características próprias de diferentes gêneros" (BRASIL, 1998, p. 25). O documento também explicita que "cabe à escola ensinar o aluno a utilizar a linguagem oral no planejamento e realização de apresentações

\footnotetext{
${ }^{5}$ Utilizamos neste artigo a versão homologada que contempla todas as etapas do ensino básico, Ensino Infantil, Ensino Fundamental e Ensino Médio (BRASIL, 2018).
} 
públicas: realização de entrevistas, debates, seminários, apresentações teatrais etc." (BRASIL, 1998, p. 25).

Para esse ensino, os PCN (BRASIL, 1998) mencionam que, no processo de escuta $^{6}$ de textos orais, espera-se que o aluno possa desenvolver sua aprendizagem sobre conhecimentos discursivos, identificar os elementos não-verbais, utilizar a linguagem escrita, quando for necessário, reconhecer as intenções do enunciador. Já no processo de produção de textos orais, espera-se que o aluno planeje sua fala (usar a escrita quando for necessária), considere o contexto (lugar, participantes), considere os elementos não-verbais; monitore o desempenho oral (BRASIL, 1998). A partir desses processos, os PCN (BRASIL, 1998) ilustram alguns gêneros textuais que podem privilegiar a produção oral: cordel, canção, notícia, entrevista, debate, depoimento, exposição, seminário, dentre outros. Dessa forma, podemos notar que os PCN abordam os gêneros orais como objeto de ensino, levando em considerações suas características e contexto de produção. Como também evidencia Baumgärtner (2015, p. 93), um dos pontos positivos a ser atribuído aos PCN é a "inserção de gêneros orais como conteúdo no ensino de língua materna".

Outro documento importante para o nosso contexto de educação é o "Currículo do Estado de São Paulo de Língua Portuguesa7", elaborado em 2008, e que tem como objetivo contribuir para a qualidade do ensino nas escolas estaduais. Além desse documento básico, há materiais de apoio como o "Caderno do gestor", tendo como finalidade contribuir no auxílio de gestores escolar, e também, os "Cadernos do Professor" e do "Aluno", destinado aos professores e aos alunos. As competências da leitura e da escrita são priorizadas no documento: "O Currículo proposto tem por eixo a competência geral de ler e de produzir textos, ou seja, o conjunto de competências e habilidades específicas de compreensão e de reflexão

\footnotetext{
${ }^{6} \mathrm{O}$ documento traz em nota de rodapé a sua compreensão de escuta: "Na perspectiva deste documento, a escuta refere-se aos movimentos realizados pelo sujeito para compreender e interpretar textos orais." (BRASIL, 1998, p. 35).

${ }^{7}$ Neste trabalho, observaremos a segunda edição do Currículo, elaborada no ano de 2012.
} 
crítica intrinsecamente associado ao trato com o texto escrito" (SÃO PAULO, 2012, p. 18). Indica ainda que cada uma das situações de aprendizagem pode ser compreendida como uma proposta de sequência didática e que em cada situação de aprendizagem são desenvolvidos: estudo de conteúdos em que são apresentadas características de um gênero ou tipologia, aspectos gramaticais para o desenvolvimento de "habilidades leitoras e escritoras (a coesão e a coerência, por exemplo) e de oralidade (estudo de gêneros orais, como apresentações ou debates, entre outros)". (SÃO PAULO, 2012, p. 39, grifo nosso). É apenas nesta citação sobre o desenvolvimento da situação de aprendizagem em que o documento faz uma breve exemplificação de gêneros orais.

No decorrer do Currículo de Língua Portuguesa, na etapa do Ensino Fundamental anos finais, a oralidade é explicitada como leitura oral, na qual há uma preocupação com a qualidade da leitura: "leitura oral: ritmo, entonação, respiração, qualidade da voz, elocução e pausa" (SÃO PAULO, 2012, p. 50). Em alguns momentos, o estudo do gênero oral é explicitado: "apresentação oral, roda de conversa", mencionando-se também "oralidade e escrita", sem especificação do gênero. No quadro de conteúdo do Ensino Médio, leva-se em consideração alguns quesitos da oralidade, tais como estratégias de escuta e a importância de tomada de turno. Em alguns momentos, são evidenciados, no campo de estudo "leitura e produção escrita", gêneros a serem trabalhados no contexto escolar tendo como foco a leitura e escrita; o foco no oral e na escrita aparece apenas no gênero "discurso".

Notamos, assim, que há uma proposta de trabalhar os gêneros orais e suas características, conforme explicitado no documento do Estado de São Paulo, entretanto, as proposições são superficiais. $O$ documento indica que os conteúdos a serem ensinados estão associados a diferentes habilidades, tais como leitura, escrita, oralidade, audição e estudos de aspectos gramaticais (SÃO PAULO, 2012). Também menciona que, a linguagem verbal (oral e escrita) propicia a compreensão dos 
discursos em diferentes áreas da sociedade, apesar de haver pouca explicitação dos gêneros orais no Currículo do Estado de São Paulo.

Ferraz e Gonçalvez (2015) analisam o Referencial Curricular da Rede Estadual de Ensino do Mato Grosso do Sul, para o ensino fundamental e discutem o lugar da oralidade na escola pública. Embora produzidos em contextos estaduais diferentes, alguns fatores são semelhantes aos que observamos no Currículo do Estado de São Paulo, tais como a falta de orientação do ensino com o oral, a não definição do que sejam os gêneros orais e a há prevalência da produção escrita.

Análise semelhante fizeram Barbosa, Santana e Lima (2018), ao investigarem, nos materiais didáticos de Ensino Médio "Caderno do Professor/Caderno do Aluno" de Língua Portuguesa, como é apresentado o ensino da oralidade. As autoras evidenciam que a oralidade está configurada no material sob a forma de conversas entre professor e alunos, dessa forma, afirmam que "falta sistematização para o ensino da elaboração de gêneros orais secundários e para a compreensão da oralidade formal nas práticas sociais" (BARBOSA; SANTANA; LIMA, 2018, p. 103).

Outro importante documento que foi inserido recentemente em nosso contexto educacional é a Base Nacional Comum Curricular (BNCC). No final do ano de 2017, foi homologada a $3^{a}$ versão da BNCC do Ensino Infantil e Ensino Fundamental e, no ano de 2018, a do Ensino Médio. No eixo da oralidade ${ }^{8}$, o documento compreende que essas práticas de linguagem "ocorrem em situação oral com ou sem contato face a face", envolvendo também "a oralização de textos em situações socialmente significativas e interações e discussões envolvendo temáticas e outras dimensões linguísticas do trabalho nos diferentes campos de atuação." (BRASIL, 2018, p. 78-79). Especificamente em relação ao trabalho com as práticas de linguagem de oralidade, o documento estabelece que se devem levar em

\footnotetext{
${ }^{8}$ Para a BNCC os eixos relacionam-se com as práticas de linguagem situadas e são divididos em quatro eixos: leitura, produção de textos, oralidade e análise linguística/semiótica. Essas práticas de linguagens são organizadas em campos de atuação, ou seja, campos onde essas práticas se realizam. (BRASIL, 2018).
} 
consideração os seguintes aspectos: condições de produção, diferenças estilísticas e linguísticas, multimodalidade, multissemiose, compreensão do texto, produção de textos orais, efeitos de sentidos provocados pelo uso de recursos linguísticos e multissemióticos e relação entre fala e escrita, citando como exemplo, aula dialogada, webconferência, mensagem gravada, jingle, seminário, debate, programa de rádio, contação de histórias, oralização de textos, vlog de game, vídeos, podcasts, dentre outros. (BRASIL, 2018) ${ }^{9}$. Em relação especificamente ao seminário, esse gênero está presente no "Campo das práticas de estudo e pesquisa"10, embora também, o gênero a apresentação oral esteja contemplado no "Campo de vida pública"11 e do "Campo das práticas de estudo e pesquisa". Assim, podemos observar que há um enfoque para os gêneros orais seminário e apresentação oral em contextos de pesquisas e de vida pública (discussão de posicionamentos, atuação política e social).

Na BNCC (BRASIL, 2018), notamos que há uma preocupação com o escutar, falar, planejar e a relação entre o oral e o escrito, elementos paralinguísticos e cinésicos, dando sinais também, da importância do outro/sujeito ouvinte em uma apresentação oral, isto é, habilidades de escuta, de formas de tratamento, de aspectos não linguísticos (olhar, riso, expressão corporal, tom de voz), são levados em consideração no ensino de gêneros orais, tais como já preconizaram Schneuwly e Dolz (2004).

Diante do exposto na BNCC (BRASIL, 2018), ressaltamos que, além de uma pesquisa de conteúdo e exposição, o documento contempla que as habilidades ao se trabalhar o gênero seminário/apresentação oral englobam outros aspectos, tais como: organização, duração, contexto, elementos paralinguísticos e cinésicos,

\footnotetext{
${ }^{9}$ A BNCC evidencia que há aspectos da prática de linguagem da oralidade em outros eixos, tais como leitura e produção de texto.

10 O Campo das práticas de estudo e pesquisa é destinado a "ampliar e qualificar a participação dos jovens nas práticas relativas ao estudo e à pesquisa" (BRASIL, 2018, p. 150).

11 O Campo de vida pública tem o objetivo de "ampliar e qualificar a participação dos jovens nas práticas relativas ao debate de ideias e à atuação política e social" (BRASIL, 2018, p. 146).
} 
memorização e ferramentas de apoio para as apresentações, com o uso da tecnologia, por exemplo, o uso de slides, possibilitando ao estudante, segundo o documento, aprender práticas de linguagens diversificadas, tais como oral, escrita, corporal, visual, sonora e digital.

Em síntese, dentre os principais documentos que prescrevem o agir do professor em contexto educacional, destacamos que os PCN (BRASIL, 1998) apresentam consolidações para o trabalho com os gêneros textuais (oral e escrito) e o Currículo do Estado de São Paulo apresenta uma predominância com o trabalho com gêneros escritos e um apagamento dos gêneros orais secundários. Já na BNCC, podemos notar que a presença dos gêneros orais se mantém como nos PCN, com ênfase nas habilidades a serem trabalhadas em cada ano do contexto escolar e nos usos da tecnologia para o auxílio de ensino e aprendizagem dos gêneros, tanto os já consagrados como outros da cultura digital multimodais.

\section{O seminário: da ausência nos manuais e nas normas acadêmicas às pesquisas crescentes}

Nas atividades acadêmicas, a apresentação oral está presente nas disciplinas em formas de seminários, nas comunicações em congressos e eventos científicos, apresentação de trabalho de conclusão de curso (TCC), e em apresentações de dissertações e de teses. A normatização para essas apresentações não foi encontrada nem na Associação Brasileira de Normas técnicas (2018), seguida por muitas instituições, nem em sites de instituições ou em normatizações acadêmicas ${ }^{12}$. Em todos os documentos pesquisados, constatamos apenas normas para trabalhos escritos como monografias, dissertações e teses. Não se leva em consideração que grande parte dos trabalhos acadêmicos em final de processo (iniciação científica,

\footnotetext{
12 Materiais consultados: 1) Universidade de São Paulo (2016); 2, Universidade Estadual de Campinas (2018); 3, Instituto de Biociências, Letras e Ciências Exatas - UNESP (2019).
} 
bancas de defesa diversas) é apresentada oralmente para uma banca e avaliados por ela. Se, por um lado, os gêneros orais, especificamente o seminário ou apresentação oral no ensino superior, não adentraram na elaboração dos manuais acadêmicos (geralmente denominados manuais de escrita acadêmica), por outro, já são objeto de estudo nas pesquisas desenvolvidas.

Focaremos em duas obras principais para sintetizar o que é dito sobre o oral como objeto de ensino e mais especificamente, sobre o gênero seminário: Gêneros orais e escritos na escola (SCHNEUWLY; DOLZ, 2004) e Gêneros orais no ensino organizado por Bueno e Costa-Hübes (2015).

Na obra Gêneros orais e escritos na escola, alguns capítulos são dedicados ao ensino do oral: o capítulo que defende o oral como objeto de ensino (DOLZ; SCHNEUWLY, 2004; DOLZ; SCHNEUWLY; HALLER, 2004; SCHNEUWLY, 2004); o da explicação da sequência didática para o oral e para a escrita (DOLZ; NOVERRAZ; SCHNEUWLY, 2004); o relato da elaboração de uma sequência didática sobre o gênero debate público regrado (DOLZ; SCHNEUWLY; DE PIETRO, 2004) e o que exemplifica uma sequência didática do gênero exposição oral (DOLZ et al., 2004).

Na obra Gêneros orais no ensino (BUENO; COSTA-HÜBES, 2015), novos gêneros para o ensino-aprendizagem são trazidos à cena, tais como a improvisação teatral e a escrita de uma esquete (DOLZ; GAGNON, 2015),a notícia televisiva (BAUMGÄRTNER, 2015; COSTA-HUBES; SWIDERSKI, 2015), o discurso de formatura (DOLZ; BUENO, 2015), o comentário jornalístico e a entrevista oral (DOLZ; MESSIAS, 2015), o debate oral coletivo (NASCIMENTO, 2015), a entrevista de emprego (SOUZA; CRISTOVÃO, 2015), a parlenda (BARRICELLI, 2015), a exposição oral e o debate para turmas de um curso de português língua estrangeira (LEURQUIN, 2015), e os gêneros orais e escritos nas aulas de matemática dos anos iniciais (LUVISON; GRANDO, 2015).

Vemos assim, um crescente nas pesquisas e trabalhos com os gêneros orais para diferentes públicos e em diversos contextos escolares. Sintetizamos, dessas 
obras, o que foi pesquisado sobre o seminário para preenchermos a lacuna existente com as reflexões que aqui trazemos, tanto do ponto de vista teórico, ao abordarmos a questão da escuta no seminário, apoiando-nos em Jakubinskij (2015), quanto de dispositivo didático prático, com a ficha de avaliação aqui proposta.

Dolz et al. (2004) definem a exposição oral como um gênero textual público, forma e específico em que "um expositor especialista dirige-se a um auditório, de maneira (explicitamente) estruturada, para Ihe transmitir informações, descreverIhe ou the explicar alguma coisa." (DOLZ et al., 2004, p. 218). Os autores afirmam que, em comparação com outras atividades orais, a exposição oral (mais conhecido no Brasil como seminário) é utilizada com frequência em salas de aula, entretanto, apesar de não haver um verdadeiro trabalho didático para o ensino desse gênero. Assim, os autores reconhecem que a exposição oral precisa ser tratada como objeto de ensino, e defendem que, ao se realizar uma intervenção didática, precisa-se levar em consideração as dimensões comunicativas do gênero, questões ligadas ao conteúdo, assim como e aspectos mais técnicos, tais como procedimentos linguísticos e discursivos do gênero oral (DOLZ et al., 2004).

Considerando que para um gênero ser ensinado é necessário conhecer suas características e sua função na sociedade, Dolz et al. (2004) constroem um modelo didático do gênero textual exposição oral. A partir da construção desse modelo, os autores (2004) elencaram alguns objetivos necessários para o domínio desse gênero: tomada de consciência da situação de comunicação, exploração das fontes de informação, estruturação de uma exposição, desenvolvimento das capacidades de exemplificação, ilustração e explicação, uso de reformulação, desenvolvimento de competência meta discursiva, importância da voz, do olhar, da atitude corporal; da preparação e da oralização das notas.

Outra pesquisa sobre o gênero seminário e sua importância no contexto escolar é a de por Goulart (2005). Em sua pesquisa, a autora analisa o seminário em uma $8^{a}$ série, antes e após seu ensino. Segundo a autora, o ensino do gênero 
por meio de uma proposta de intervenção didática em parceira com uma professora, foi um instrumento mediador fundamental no desenvolvimento de habilidades de leitura, escrita e produção de fala em contextos formais escolares e extra-escolares, além de proporcionar a autonomia dos alunos em relação à tomada da palavra (GOULART, 2005).

A pesquisa de Gonçalves e Bernardes (2010), por sua vez, procurou conhecer, por meio de aplicação de questionários em três escolas de Dourados/MS, a prática do seminário no contexto escolar. Obtiveram como resultado que a proposta do gênero seminário é maior no Ensino Médio e as vantagens mencionadas pelos discentes foram: a possibilidade de se fazer uma aula diferente, o aprendizado da fala frente a um público e o trabalho em grupo. Os obstáculos apontados foram a dificuldade do falar em público para os discentes, e a duração do tempo da aula para os docentes.

Lousada, Rocha e Guimarães-Santos (2015) propõem um projeto didático com diferentes gêneros para o ensino do francês como língua estrangeira. As autoras organizaram um currículo baseado em tipos de agir social em um contexto de intercâmbio. A partir da organização do currículo, apresentaram o agir social "apresentar trabalhos escolares" como um guarda-chuva que engloba diferentes gêneros: exposição ou comunicação oral, power point da comunicação, handout, resumo, síntese, compte rendu e relatório científico. As autoras também sintetizam as características da exposição oral, elaborando um quadro baseado em Schneuwly e Dolz (2004), em que estão presentes contexto de produção, características linguísticas e discursivas, dimensões multimodais / extralinguísticas e suporte para a apresentação.

Outro estudo sobre a exposição oral é o de Gomes-Santos (2012), intitulado "A exposição oral: nos anos iniciais do ensino fundamental", destinado a professores de modo geral. Nele, o autor aborda, por meio de três gêneros textuais (artigo de divulgação, entrevista e programa televisivo), aspectos sobre a exposição oral. 
Propõe uma organização global do gênero para os alunos dos primeiros anos do ensino fundamental, baseados nos autores Dolz et al. (2004). Além de sugerir atividades, propõe uma grade de avaliação, elaborada coletivamente com os alunos.

O auditório e a problemática da escuta, um dos aspectos que discutiremos neste artigo, são abordados por alguns dos autores aqui revisados. Dolz et al. (2004) trazem essa questão, mencionando a importância do auditório em uma apresentação oral; explicitam que o expositor precisar estar atento aos sinais do auditório e, dependendo da situação, gerenciar mudanças em sua exposição. Mencionam também que a fase conclusiva da exposição oral pode também ser o início de um diálogo com os ouvintes: "submeter aos ouvintes um problema novo, desencadeado pela exposição, ou, ainda, dar início a um debate etc." (DOLZ et al., 2004, p. 221).

Gomes-Santos (2012, p. 133) também menciona que a exposição oral é um "momento de intensa negociação", pois algumas reações do auditório podem ser percebidas pelo expositor durante a apresentação. Para ele, o auditório pode reagir de duas maneiras. A primeira, uma reação simultânea, como por exemplo, a risada dos ouvintes. A outra maneira é o momento de perguntas e comentários, formuladas pelo auditório, avaliativos ou não, após o encerramento da exposição.

Após essa síntese das pesquisas sobre o gênero aqui abordado, aprofundaremos duas questões pouco desenvolvidas nos trabalhos sobre esse gênero: uma proposta de ficha avaliativa e a questão do público e da escuta desse público durante a apresentação do seminário.

\section{A ficha de avaliação como instrumento de formação docente}

A ficha de avaliação do seminário oral aqui apresentada (Quadro 2) foi desenvolvida no segundo semestre de 2012 e modificada, ampliada e utilizada, desde então, para avaliar discentes de diversos cursos de graduação e de licenciatura em mais de uma instituição de ensino. A ficha foi elaborada a partir de 
uma sequência de atividades elaborada para uma média de seis horas de aula de trabalho (Quadro 1), com base nos pressupostos do ensino do oral desenvolvidos por Schneuwly e Dolz (2004). A seguir, apresentamos a sequência de atividades. 


\section{Quadro 1 - Atividades didáticas (parte de uma SD sobre ensino de seminário)}

\section{Conhecimento prévio} aspectos:

Você já apresentou um seminário? Como foi? Para você, o que é um seminário? Para responder, pense sobre os seguintes

- público-alvo;

- objetivo;

- $\quad$ expositor (papel social);

- local de exposição

- linguagem utilizada;

- $\quad$ postura adequada;

- vestuário adequado;

- voz;

- gestos;

- tema abordado

- outros:

2. Guia para a preparação e a apresentação de um seminário.

A. Etapas para se preparar/apresentar um seminário:

\section{Antes}

a. Definição do tema e da pesquisa.

b. Distribuição de tarefas.

c. Organização do material.

d. Elaboração do plano de apresentação.

\section{Durante}

e. Apresentação dos membros e do plano de exposição.

f. Desenvolvimento e encadeamento dos diferentes tópicos relacionados ao tema.

g. Recapitulação e síntese.

h. Conclusão/Encerramento.

\section{Depois}

i. Auto-avaliação.

j. Conhecer a avaliação dos participantes/ouvintes.

B. Procedimentos para a pesquisa, preparação e apresentação do seminário:

- Reunir-se previamente com todo o grupo e preparar o trabalho juntos, podendo ser dividido para fins de pesquisa e apresentação.

- Compreender com clareza todo o assunto a ser tratado pelo grupo e assumir a parte do colega, no dia da apresentação, caso seja necessário.

- $\quad$ É necessário ensaiar previamente; não basta dar uma lida.

- Levar roteiro para ser consultado.

- $\quad$ Não se deve memorizar tudo a ser falado, mas ensaiar e dominar o tema.

3. Observe, no quadro abaixo, os aspectos não-linguísticos que também devem ser levados em consideração na preparação do seminário. Em que esses aspectos podem ajudar ou atrapalhar uma apresentação?

\begin{tabular}{|l|l|l|l|l|}
\hline \multicolumn{1}{|c|}{$\begin{array}{c}\text { Meios para- } \\
\text { linguísticos }\end{array}$} & \multicolumn{1}{|c|}{ Meioscinésicos } & \multicolumn{1}{|c|}{$\begin{array}{c}\text { Posição dos } \\
\text { locutores }\end{array}$} & \multicolumn{1}{c|}{$\begin{array}{c}\text { Aspecto exterior } \\
\text { lugosição dos }\end{array}$} \\
\hline $\begin{array}{l}\text { Qualidade da voz } \\
\text { Pausas Respiração }\end{array}$ & Atitudes corporais & Ocupação de lugares & Roupas & Lugares \\
Risos & Movimentos & Espaço pessoal & Penteado & $\begin{array}{l}\text { Iluminação } \\
\text { Disposição das cadeiras } \\
\text { Suspiros }\end{array}$ \\
\hline
\end{tabular}

Fonte: Schneuwly, B; Dolz, J e colaboradores. Gêneros e orais e escritos na escola. Campinas: Mercado de Letras. 2004.

4. Além da linguagem verbal e não verbal, há materiais de suporte que podemos utilizar para facilitar a compreensão e o acompanhamento das informações. Veja alguns:

- gráficos;

- $\quad$ figuras, ilustrações, fotografias, imagens;

- textos de jornais, revistas, internet, etc.

- DVD; filme (ou techo) do youtube;

- lousa e giz;

- $\quad$ slides no power point

- outros.

5. Para você, o que significa participar de um seminário enquanto público? Discuta com seus colegas a função dos ouvintes.

6. Você acha que a nota de um seminário deve ser:

a) individual ou

b) uma mesma nota para todo o grupo?

Justifique sua escolha. 
Fonte: elaborado pelo autor.

No que concerne à ficha, ela foi criada a partir da avaliação que graduandos de quatro cursos de uma instituição pública federal da cidade de São Paulo (duas engenharias e dois cursos tecnólogos) fizeram da apresentação oral de seus colegas. A proposta da ficha de avaliação aqui sintetizada é o resultado da categorização desse trabalho de avaliação pautado nos critérios estabelecidos pelos alunos-ouvintes conforme os efeitos de sentido que as apresentações orais causaram neles, após as atividades trabalhadas sobre o gênero. 
Quadro 2 - Ficha de (auto)avaliação de seminário ou apresentação oral

\begin{tabular}{|c|c|c|c|c|}
\hline Tópico avaliado & \multicolumn{2}{|c|}{ Subtópico avaliado } & Avaliação & Justificativa \\
\hline \multirow{5}{*}{ Tema e pesquisa } & \multirow{2}{*}{\multicolumn{2}{|c|}{ Escolha do tema }} & ( ) Pertinente & $\begin{array}{l}\text { De interesse a todos; pertinente com } \\
\text { o curso. }\end{array}$ \\
\hline & & & $\begin{array}{l}\text { ( ) Impertinente (pouco } \\
\text { pertinente) }\end{array}$ & Muito técnico; muito complexo. \\
\hline & \multirow{3}{*}{\multicolumn{2}{|c|}{ Preparação/pesquisa material }} & ( ) Ótimo, bom & \\
\hline & & & ( ) Regular & \\
\hline & & & ( ) (Relativamente) fraca & Insuficiente; ficou superficial. \\
\hline \multirow{10}{*}{ Apresentação } & \multirow{3}{*}{\multicolumn{2}{|c|}{ Saber explicar o tema escolhido }} & ( ) Fugiu ao tema & \\
\hline & & & $\begin{array}{l}\text { ( ) Soube explicar } \\
\text { (sub)tema }\end{array}$ & \\
\hline & & & ( ) Regular & $\begin{array}{l}\text { Faltaram dados; faltaram exemplos; } \\
\text { muito rápido; muito objetivo/sucinto. }\end{array}$ \\
\hline & \multicolumn{2}{|c|}{0 texto (oral-escrito) } & $\begin{array}{l}\text { ( ) } \\
\text { Abertura/Desenv./Encerr. } \\
\text { ( ) Relação clara entre as } \\
\text { partes } \\
\text { ( ) Outro }\end{array}$ & $\begin{array}{l}\text { Falou com começo, meio e fim e as } \\
\text { partes estavam ligadas entre si; } \\
\text { faltou continuidade, desviou do } \\
\text { assunto; confuso no engajamento de } \\
\text { ideias; terminou abruptamente; } \\
\text { ausência de bibliografia; faltou se } \\
\text { apresentar; erro conceitual. }\end{array}$ \\
\hline & \multirow{2}{*}{\multicolumn{2}{|c|}{$\begin{array}{c}\text { Interação com o público; contato } \\
\text { visual }\end{array}$}} & ( ) Boa & Interage, olha para todos. \\
\hline & & & ( ) Regular/fraca & $\begin{array}{l}\text { Não olha para o público, não } \\
\text { interage, olha só para o slide, olha só } \\
\text { para um lado. }\end{array}$ \\
\hline & \multirow{2}{*}{\multicolumn{2}{|c|}{ "Timing" }} & ( ) Adequado & \\
\hline & & & ( ) Inadequado & Muito rápido; muito demorado. \\
\hline & \multirow{2}{*}{\multicolumn{2}{|c|}{ Escolhas linguísticas }} & $\begin{array}{l}\text { ( )Apropriadas à situação } \\
\text { de comunicação }\end{array}$ & \\
\hline & & & $\begin{array}{l}\text { ( ) Inapropriadas à } \\
\text { situação de comunicação }\end{array}$ & $\begin{array}{l}\text { Uso de gírias; piadas inapropriadas; } \\
\text { vícios de linguagem (é... tipo... ok?), } \\
\text { gerundismo. }\end{array}$ \\
\hline \multirow{12}{*}{ Apresentação } & \multirow{2}{*}{\multicolumn{2}{|c|}{ Gestos/posição corporal }} & ( ) Adequados & \\
\hline & & & ( ) Inadequados & $\begin{array}{l}\text { Poucos gestos (muito parado); mexeu } \\
\text { no cabelo em excesso; pernas } \\
\text { abertas; chutou o ar; dançou; ficou } \\
\text { sentado; mascou chicletes. }\end{array}$ \\
\hline & & Dicção & $\begin{array}{l}\text { ( ) Boa } \\
\text { (...) Regular }\end{array}$ & $\begin{array}{l}\text { Gaguejou; tom de voz muito baixo; } \\
\text { tom de voz único; dá sono. }\end{array}$ \\
\hline & & Atitude & $\begin{array}{l}\text { Demonstrou: } \\
\text { ( ) tranquilidade } \\
\text { ( ) nervosismo } \\
\text { ( ) timidez } \\
\text { ( ) outro } \\
\end{array}$ & $\begin{array}{l}\text { Conhecia o assunto, mas o } \\
\text { nervosismo atrapalhou um pouco; } \\
\text { embora estivesse nervoso, mostrou } \\
\text { saber o conteúdo; estava distraído. }\end{array}$ \\
\hline & \multirow{3}{*}{\multicolumn{2}{|c|}{$\begin{array}{c}\text { Integração entre os membros do } \\
\text { grupo }\end{array}$}} & ( ) Boa & \\
\hline & & & $\begin{array}{l}\text { ( ) Necessita uma melhor } \\
\text { integração }\end{array}$ & \\
\hline & & & ( ) Ausente & \\
\hline & \multirow{5}{*}{$\begin{array}{c}0 \\
\text { suporte }\end{array}$} & \multirow[t]{2}{*}{ Slides } & ( ) Uso de imagens & $\begin{array}{l}\text { Slides ricos em imagens; muita foto; } \\
\text { faltou "equacão" entre textos e } \\
\text { imagens; slides escuros. }\end{array}$ \\
\hline & & & ( ) Uso de textos & Pouca informação; muito texto. \\
\hline & & Outro: vídeo & & Vídeo muito longo \\
\hline & & \multirow[b]{2}{*}{$\begin{array}{l}\text { Interação fala-suporte } \\
\text { (ausência do suporte) }\end{array}$} & ( ) Uso de imagens & Imagens auxiliando a apresentação. \\
\hline & & & ( ) Uso de textos & $\begin{array}{l}\text { Muita leitura dos slides; fala } \\
\text { divergente do slide; boa fala, mesmo } \\
\text { sem auxilio de slides; olhar a } \\
\text { "colinha" de forma mais discreta. }\end{array}$ \\
\hline \multirow{2}{*}{\multicolumn{3}{|c|}{ Vestimenta }} & ( ) Adequada & \\
\hline & & & () Inadequada & Uso de chinelo; decote acentuado. \\
\hline
\end{tabular}

Fonte: elaborado pelo autor. 
Essa ficha de avaliação tem sido utilizada desde então em diferentes contextos. Neste artigo, apresentamos o uso da ficha nas aulas nos cursos de Letras na Universidade Estadual Paulista, na disciplina intitulada "Prática de Leitura e Produção de Textos II", ministrada aos alunos do $2^{\circ}$ ano de Letras (diurno e noturno) em que o seminário é trabalhado enquanto gênero. 0 trabalho consiste inicialmente no trabalho com as atividades (Quadro 1 ) sobre 0 seminário/apresentação oral, em que os alunos discutem o gênero tanto em relação às suas próprias experiências escolares quanto em relação a trechos de apresentações orais. A ficha de avaliação (Quadro 2) também é discutida com os alunos. Os alunos leem e discutem texto teórico sobre o tema, especificamente "A exposição oral" (DOLZ et al., 2004) e as etapas do seminário, os aspectos linguísticos, não linguísticos, assim como a entrada desse gênero na escola e seu trabalho com ele como futuros professores são discutidos em sala. Após esse trabalho, os alunos devem selecionar um tema de interesse do grupo e pesquisar sobre ele. Após aproximadamente três meses de trabalho de pesquisa, os estudantes apresentam o seminário sobre o tema escolhido no tempo estipulado. Antes da apresentação em si, os estudantes passam por diversos momentos de discussão em sala sobre diferentes elementos constitutivos do seminário. Inicialmente, apresentam e discutem o tema do seminário com os colegas da sala; em seguida, escrevem o objetivo e as perguntas de pesquisa que pretendem responder, em atividade elaborada com base em Machado, Lousada e Abreu-Tardelli (2005), e, após discussão com a sala e com o professor, reescrevem seus objetivos e perguntas. Após a apresentação do seminário, todos os alunos da sala avaliam o grupo que apresentou com base na ficha, no entanto, a avaliação é feita por escrito, na forma dissertativa e não apenas assinalada na folha. $O$ intuito, com isso, é que a ficha sirva como norteadora e não como um dispositivo para um preenchimento automático. Concomitantemente a isso, os alunos que apresentaram devem fazer a auto-avaliação da apresentação feita. As avaliações são depois entregues aos 
respectivos apresentadores para que tomem conhecimento do efeito que suas apresentações causaram nos ouvintes.

$\mathrm{Na}$ ficha, os alunos são avaliados tendo em vista o papel social de estudante universitário, em que deverá apresentar seminários, nas mais diversas disciplinas, assim como em seu potencial papel de pesquisador em formação, quando deverá apresentar seu trabalho de iniciação científica em eventos científicos destinados à graduação. Com isso, cria-se a oportunidade de discutir com a sala como deve ser feita uma avaliação, contendo comentários que destaquem os aspectos positivos e apontem melhorias a serem feitas. Assim, a avaliação é realizada por todos os ouvintes, ou seja, os demais alunos do curso e o próprio professor.

O objetivo secundário do trabalho com esse gênero na disciplina, mas não menos importante, desenvolvido por meio das discussões dos textos teóricos lidos e da sequência didática trabalhada, é que os alunos possam refletir sobre suas futuras ações como professores em sala de aula, em um trabalho com o oral enquanto objeto de ensino. Dessa forma, espera-se que suas vivências enquanto aprendizes, revividas nas discussões fomentadas pela sequência didática, possam ir além do seminário enquanto objeto de avaliação de conteúdo, transformando-se em objeto a ser ensinado como futuros professores.

Em relação à efetiva realização do trabalho com o seminário realizado na disciplina, levantamos a questão da possibilidade ou não da transposição de um saber-fazer, ou seja, se teríamos êxito, através desse tipo de atividade, em conseguir que o estudante abrace as práticas efetivas do oral em sua sala de aula após o egresso da universidade. Para que seja uma prática que possa ser rediscutida, acreditamos que a inclusão de atividades do oral nos momentos da prática dos licenciandos em sala de aula potenciaria esse saber-fazer. No Brasil, esse movimento encontra dois espaços para que possa se efetivar: nos programas de PIBID (Programa Institucional de Bolsas de Iniciação à Docência) ou nos estágios dos cursos de licenciatura. 
Ao comparar a grade de avaliação de Gomes-Santos (2012) com a ficha avaliativa aqui proposta, podemos notar algumas similaridades. A grade de avaliação apresentada por Gomes-Santos (2012) abrange questões dissertativas, em que o aluno/ouvinte fará uma reflexão através das perguntas elencadas sobre (i)organização global da exposição, (ii) o conteúdo da exposição, (iii) a forma de exposição dos conteúdos (distribuição do conteúdo; transição verbal entre os participantes; utilização de estratégias; utilização de recursos - gestos, voz, olhar e; utilização de instrumentos), (iv) o auditório (relação entre auditório e grupo) e por fim, (v) sugestões de aperfeiçoamento da exposição. Já a ficha de Abreu-Tardelli (Quadro2) aborda tópicos da apresentação oral a serem avaliados pela assinalação por características avaliativas (pertinente, bom, regular) e por justificativa.

Ao compararmos os dois instrumentos de avaliação, podemos notar aspectos muitos similares, tais como escolha do tema, preparação do material, explicação do tema, interação com o público, escolhas linguísticas, gestos e posições corporais, interação entre os membros do grupo, suporte. Em relação aos conteúdos diferentes, observamos o fator "auditório" em Gomes-Santos (2012), pois o autor avalia além da relação entre o grupo e o auditório, mas também, a relação do auditório com o público. Abreu-Tardelli (Quadro 2) traz um novo tópico para ser avaliado, o quesito "vestimenta", ou seja, avaliar a adequação do traje usado pelo expositor à situação, assim como a atitude do expositor.

\section{O ensino do oral: um privilégio da fala?}

Vemos pelas pesquisas já desenvolvidas que o oral, enquanto objeto de ensino, tende a privilegiar a fala e isso pode parecer, em um primeiro momento, óbvio. No texto, A exposição oral (DOLZ et al., 2004), é dado um foco grande ao expositor, cabendo aos ouvintes o papel de avaliadores do colega que fala: "os alunos-ouvintes do conjunto da turma podem ser convidados a fazer uma crítica das 
apresentações" (DOLZ et al., 2004, p. 243). Nossa reflexão aqui é ampliar a reflexão sobre o papel do ouvinte sobre quem expõe.

Se partirmos das mais diversas situações de comunicação dos gêneros orais para fazermos a transposição didática do gênero em contexto escolar, teremos sempre, como nos faz pensar Jakubinskij (2015), as duas ações no processo de interação: ora na escuta, ora na fala, um interdependente do outro. Mesmo em situações mais "monológicas", ou seja, em que a interação não será automática (como em uma apresentação em contexto acadêmico, por exemplo), ela continua acontecendo na mente ou nos gestos, nas mímicas e nos sinais do interlocutor (JAKUBINSKIJ, 2015). Em um relato feito a nós sobre a participação em uma entrevista de emprego, um aluno menciona que seu entrevistador dormiu enquanto ele, entrevistado, falava. Sua reação imediata foi de pânico: será "pegadinha"? "o que faço?" "devo acordá-lo?" "deixo dormir?", "continuo falando?". Apesar de ser um exemplo extremo e, cremos que pouco comum, serve para pôr em evidência a importância do papel do outro na reação e continuidade da fala de um expositor. Afinal, espera-se que um expositor saiba falar, expor o conteúdo sobre o qual se preparou para falar, mas também deve haver momentos que deve saber ouvir e reagir às interações verbais ou não-verbais de sua audiência, como corroboram Dolz et al. (2004, p. 219): "ao longo da exposição, avaliar a novidade, a dificuldade daquilo que expõe - permanecendo atento aos sinais que the são enviados pelo auditório, e, na medida do necessário, dizer de outra maneira, reformular, definir."

Nesse sentido, faz-se necessário desconstruir o mito tão disseminado entre os alunos ao se trabalhar o seminário em sala de aula: "se você é meu colega, não faça perguntas após minha apresentação". Há dois pressupostos implícitos na expectativa dessa (re)ação silenciosa por parte dos colegas: (i) a de que fazer perguntas pode desestabilizar o apresentador, pois ele pode não saber responder $\mathrm{e}$ (ii) a de que é necessário ter o conhecimento de todo o saber necessário sobre o assunto exposto quando assume-se o papel do expositor. Esses dois implícitos 
necessitam ser desconstruídos, principalmente se pensarmos que alunos de Letras são alunos em formação, tanto para exercerem o papel de futuro professor, quanto para exercerem o papel de acadêmicos. Assim, é necessário, primeiramente, esclarecer que tanto professor quanto pesquisador são profissões que estão em constante interlocução, seja com o outro, seja consigo mesmo. Em segundo lugar porque o precisar interagir com o outro tem evidenciado, em nossas práticas, diferentemente da hipótese dos alunos, uma contribuição no processo de desenvolvimento, seja da própria fala, seja do conteúdo apresentado.

Outro relato de nossa prática universitária para ilustrar a importância significativa que um interlocutor pode assumir na exposição de alguém foi o nervosismo demasiado de um estudante que conseguiu fazer sua apresentação porque obteve auxílio dos colegas (do auditório, pois, nesse caso, a apresentação era individual), através das perguntas elaboradas por eles durante sua exposição. A cada momento que a plateia percebia seu nervosismo e sua incapacidade em continuar, os ouvintes faziam perguntas e complementavam com informações que eles conheciam sobre o conteúdo sendo exposto pelo aluno. Isso possibilitou que o aluno finalizasse sua apresentação e toda a sala percebeu a relevância da interlocução que, nesse caso extremo, ficou ainda mais evidenciada.

Retomamos Jakubinskij (2015) para nos auxiliar a interpretar o que a prática realizada pelos alunos evidenciou. Segundo o autor, a percepção visual e auditiva do interlocutor é um fator determinante para a percepção da fala e para o próprio processo da fala e o autor chama a atenção que pouco se leva em consideração o papel da mímica e dos gestos no momento da interação, apesar de ele ser muito importante. Outra atividade presente em nossa sequência didática vide item 5 do Quadro 1) é a avaliação feita não somente do expositor pelo auditório, mas também do auditório pelo expositor. Esse é um item que merece ser acrescentado à nossa ficha de avaliação (esse item está presente na ficha de Gomes-Santos, 2012), pois, quando se é escutado e bem escutado, o processo de fala é facilitado (JAKUBINSKIJ, 
2015, p. 69), como ficou evidente no caso que relatamos. Além disso, se toda interação é uma inter-ação, como nos lembra Jakubinskij (2015), em razão de sua própria natureza, ela se esforça para ser bilateral e essa bilateralidade, mesmo que aqui não esteja no objeto discutido pelo autor russo (no caso, seu objeto é o diálogo cotidiano), mas em uma situação formal, merece ser destacada quando o oral é trabalhado enquanto objeto de ensino. A escuta também é colocada pelo autor como algo a ser aprendido (JAKUBINSKIJ, 2015) no diálogo cotidiano e acrescentamos que devemos introduzir essa necessidade e desenvolver essa capacidade para o contexto escolar e acadêmico que, em nossa perspectiva, parte das práticas sociais para o ensino na escola.

No caso do seminário, devemos pensar em estratégias de ensino que englobem ambos os lados da interlocução e, no caso da ficha de avaliação, que o único avaliado não seja o expositor, mas também seus ouvintes: participaram? Fizeram perguntas? De que tipo? Colaboraram com o expositor para um debate mais eficaz do tema exposto? Se essa questão teve seu espaço garantido na sequência didática (Quadro2), merece também um espaço na ficha de avaliação, afinal, avaliamos o que consideramos mais relevante. Se quisermos dar relevância à escuta, ela merece um espaço próprio no processo avaliativo.

\section{Reflexões Finais}

Resgatamos aqui algumas ponderações possibilitadas com as reflexões suscitadas com o uso da ficha de avaliação em contexto de formação inicial de professor.

O primeiro destaque a ser dado é em relação à importância do oral enquanto objeto de ensino nas duas pontas do sistema escolar: na educação primária e na superior. Na primária, para ensinar as crianças a agir em diferentes situações sociais, 
escolares ou não escolares; no superior, para se trabalhar a eficácia no contexto acadêmico-científico.

Para Dolz, Noverraz e Schneuwly (2004, p. 135, grifo do autor):

\begin{abstract}
Não existe "o oral", mas "orais" em múltiplas formas, que, por outro lado, entram em relação com os outros escritos, de maneiras muito diversas: podem se aproximar da escrita e mesmo dela depender. (...) Não existe uma essência mítica do oral que permitiria fundar sua didática, mas práticas de linguagem muito diferenciadas, que se dão prioritariamente, pelo uso da palavra (falada), mas também por meio da escrita, e são essas práticas que podem tornar objetos de um trabalho escolar. Essas práticas tomam, necessariamente, as formas mais ou menos estáveis que dominamos gêneros.
\end{abstract}

Assim, quando ensinamos um gênero oral não excluímos a escrita. Mas sim, ensinamos "atividades de linguagem realizadas oralmente, gêneros que se praticam essencialmente na oralidade ou ainda, atividades de linguagem que combinam oral e escrita.". (DOLZ; NOVERRAZ; SCHNEUWLY, 2004, p. 139).

O segundo ponto a destacar é a necessidade de se incluir atividades na sequência didática que permitam que a escuta da palavra do outro seja posta como uma aprendizagem de linguagem a ser ensinada e avaliada.

O terceiro ponto é em relação ao uso dos instrumentos externos que, ao longo do processo de aprendizagem, transformam-se em instrumentos internos. Assim, ao vermos e avaliarmos o outro apresentando, não estamos apenas avaliando o colega, mas aprendendo os efeitos de sentido que causam em nós determinados gestos, mímicas e posições. A ficha de avaliação, ao explicitar cada ação que deve ser levada em consideração na exposição, deve tornar-se, com o tempo, internalizada, sem a necessidade de ser utilizada. Nesse sentido, é um instrumento de ação docente fundamental no ensino em geral e no do oral, especificamente.

Consideramos os critérios da ficha de avaliação válidos não só para se trabalhar com alunos de nível superior, mas também para com alunos da educação básica, assim como um ponto de partida para que novos critérios sejam 
acrescentados conforme o contexto e o retorno de cada público-alvo. As avaliações e auto-avaliações também evidenciaram a importância da escuta do outro, que foi sinalizada pelos estudantes como favorecendo ou dificultando a concentração dele mesmos enquanto expositores.

Esperamos, assim, que a ficha avaliativa e o ensino da escuta possam se tornar instrumentos de formação efetivos para o trabalho em sala de aula com o seminário em que novas reflexões teóricas e metodológicas advenham de seus usos.

\section{Referências}

ABREU, Antônio Suárez. $A$ arte de argumentar: gerenciando razão e emoção. São Paulo: Ateliê Editorial, 2001.

ASSOCIAÇÃO BRASILEIRA DE NORMAS TÉCNICAS - ABNT. Disponível em: http://www.abnt.org.br/. Acesso em: 25 jan. 2018.

BARBOSA, Gislene Aparecida da Silva; SANTANA, Bianca Prates Santana; LIMA, Thaís Matias. $O$ ensino da oralidade no currículo do estado de São Paulo. Colloquium Humanarum, Presidente Prudente, v. 15, n. 1, p. 94-104, jan./mar. 2018.

BARRICELLI, Ermelinda. Parlenda como gênero oral nas séries iniciais. In: BUENO, Luzia; COSTA-HÜBES, Terezinha da Conceição (org.). Gêneros orais no ensino. Campinas, SP: Mercado de Letras, 2015. p. 277-321.

BAUMGÄRTNER, Carmem Teresinha. Grupo de estudos de língua portuguesa GELP: uma experiência de formação continuada de professores com foco em gêneros orais e ensino. In: BUENO, Luzia; COSTA-HÜBES, Terezinha da Conceição (org.). Gêneros orais no ensino. Campinas, SP: Mercado de Letras, 2015. p. 91116.

BRASIL. Ministério da Educação. Base nacional comum curricular. Brasília: MEC/CONSED/UNDIME, 2018. Disponível em: http://basenacionalcomum.mec.gov.br/wpcontent/uploads/2018/12/BNCC_19dez2018_site.pdf. Acesso em: 1 mar. 2019.

BRASIL. Ministério da Educação. Parâmetros curriculares nacionais. ensino médio. Brasília: MEC, 2000. 
BRASIL. Ministério da Educação. Parâmetros curriculares nacionais. terceiro e quarto ciclos do ensino fundamental: língua portuguesa. Brasília: MEC/SEF, 1998.

BUENO, Luzia; COSTA-HÜBES, Terezinha da Conceição (org.). Gêneros orais no ensino. Campinas, SP: Mercado de Letras, 2015. (Série Ideias Sobre Linguagem).

CÂMARA JUNIOR, Joaquim Mattoso. Manual de expressão oral e escrita. Rio de Janeiro: J. Ozon Editor, 1961.

CARNEGIE, Dale. Como falar em público e influenciar pessoas no mundo dos negócios. Rio de Janeiro: Editora Record, 1996.

COSTA-HÜBES, Terezinha da Conceição; SWIDERSKI, Rosiane Moreira da Silva. Gêneros orais e ensino: uma experiência didática com notícia televisiva. In: BUENO, Luzia; COSTA-HÜBES, Terezinha da Conceição (org.). Gêneros orais no ensino. Campinas, SP: Mercado de Letras, 2015. p. 139-168.

DOLZ, Joaquim; BUENO, Luzia. Gêneros orais e gêneros produzidos na interface escrito-oral: o discurso de formatura no ensino fundamental e sua contribuição para o letramento escolar. In: BUENO, Luzia; COSTA-HÜBES, Terezinha da Conceição (org.). Gêneros orais no ensino. Campinas, SP: Mercado de Letras, 2015. p. $117-138$.

DOLZ, Joaquim; GAGNON, Roxane. O gênero de texto, uma ferramenta didática para desenvolver a linguagem oral e escrita. In: BUENO, Luzia; COSTA-HÜBES, Terezinha da Conceição (org.). Gêneros orais no ensino. Campinas, SP: Mercado de Letras, 2015. p. 23-56.

DOLZ, Joaquim; MESSIAS, Carla. A rádio escolar como um lugar para o ensino da compreensão e produção oral. In: BUENO, Luzia; COSTA-HÜBES, Terezinha da Conceição (org.). Gêneros orais no ensino. Campinas, SP: Mercado de Letras, 2015. p. $169-198$.

DOLZ, Joaquim; NOVERRAZ, Michèle; SCHNEUWLY, Bernard. Sequências didáticas para o oral e a escrita: apresentação de um procedimento. In: SCHNEUWLY, Bernard; DOLZ, Joaquim. Gêneros orais e escritos na escola. Tradução e organização: Roxane Rojo e Glaís Sales Cordeiro. Campinas, SP: Mercado de Letras, 2004. p. 81-108.

DOLZ, Joaquim; SCHNEUWLY, Bernard. Gêneros e progressão em expressão oral e escrita: elementos para a reflexões sobre uma experiência Suíça (Francófona). In: SCHNEUWLY, Bernard; DOLZ, Joaquim. Gêneros orais e escritos na escola. Tradução e organização: Roxane Rojo e Glaís Sales Cordeiro. Campinas, SP: Mercado de Letras, 2004. p. 35-61. 
DOLZ, Joaquim; SCHNEUWLY, Bernard; DE PIETRO, Jean-François. Relato da elaboração de uma sequência: o debate público. In: SCHNEUWLY, Bernard; DOLZ, Joaquim. Gêneros orais e escritos na escola. Tradução e organização: Roxane Rojo e Glaís Sales Cordeiro. Campinas, SP: Mercado de Letras, 2004. p. 213-239.

DOLZ, Joaquim; SCHNEUWLY, Bernard; DE PIETRO, Jean-François; ZAHND, Gabriele. A exposição oral. In: SCHNEUWLY, Bernard; DOLZ, Joaquim. Gêneros orais e escritos na escola. Tradução e organização: Roxane Rojo e Glaís Sales Cordeiro. Campinas, SP: Mercado de Letras, 2004. p. 183-212.

DOLZ, Joaquim; SCHNEUWLY, Bernard; HALLER, Sylvie. O oral como texto: como construir um objeto de ensino. In: SCHNEUWLY, Bernard; DOLZ, Joaquim. Gêneros orais e escritos na escola. Tradução e organização: Roxane Rojo e Glaís Sales Cordeiro. Campinas, SP: Mercado de Letras, 2004. p. 125-158.

FERRAZ, Mariolinda Rosa Romera; GONÇALVEZ, Adair Vieira. Gêneros orais: práticas de ensino sem evidência. In: BUENO, Luzia; COSTA-HÜBES, Terezinha da Conceição (org.). Gêneros orais no ensino. Campinas, SP: Mercado de Letras, 2015. p. 57-89.

GOMES-SANTOS, Sandoval Nonato. $A$ exposição oral: nos anos iniciais do ensino fundamental. São Paulo: Cortez, 2012.

GONÇALVES, Adair Vieira; BERNARDES, Elizete de Souza. O gênero seminário: usos e dimensões ensináveis. Revista Linguasagem, São Carlos, 2010. Disponível em: http://www.letras.ufscar.br/linguasagem/edicao14/art_04.php. Acesso em: 25 mar. 2018.

GOULART, Claudia. As práticas orais na escola: o seminário como objeto de ensino. 2005. 206 f. Dissertação (Mestrado) - Universidade Estadual de Campinas, Instituto de Estudo da Linguagem, Campinas, 2005. Disponível em: http://repositorio.unicamp.br/bitstream/REPOSIP/270428/1/Goulart_Claudia_M.pd f. Acesso em: 25 mar. 2018.

INSTITUTO DE BIOCIÊNCIAS, LETRAS E CIÊNCIAS EXATAS - UNESP. São Paulo: Unesp, 2019. Estrutura do trabalho acadêmico. Disponível em: https://www.ibilce.unesp.br/\#!/biblioteca/servicosoferecidos/normalizacao/estrutura-do-trabalho-academico---orientacao/. Acesso em: 28 mar. 2019.

IVANOVA, Irina. Prefácio e apresentação. In: JAKUBINSKIJ, Lev. Sobre a fala dialogal. Tradução de Dóris de Arruda C. da Cunha, Suzana Leite Cortez. São Paulo: Parábola Editorial, 2015. 
JAKUBINSKIJ, Lev. Sobre a fala dialogal. Tradução de Dóris de Arruda C. da Cunha, Suzana Leite Cortez. São Paulo: Parábola Editorial, 2015.

LEURQUIN, Eulália Vera Lúcia Fraga. Gêneros orais em situação de ensino e aprendizagem de português língua estrangeira. In: BUENO, Luzia; COSTA-HÜBES, Terezinha da Conceição (org.). Gêneros orais no ensino. Campinas, SP: Mercado de Letras, 2015. p. 297-320.

LOUSADA, Eliane Gouvêa; ROCHA, Suélen Maria; GUIMARÃES-SANTOS, Luzia. Gêneros orais, projetos didáticos de gêneros e mobilidade estudantil: perspectivas para ensinar a agir em francês como língua estrangeira. In: BUENO, Luzia; COSTA-HÜBES, Terezinha da Conceição (org.). Gêneros orais no ensino. Campinas, SP: Mercado de Letras, 2015. p. 321-356.

LUVISON, Cidinéia da Costa; GRANDO, Regina Célia. Os gêneros orais e escritos nas aulas de matemática e sua importância para a apropriação de conceitos e linguagens matemáticas. In: BUENO, Luzia; COSTA-HÜBES, Terezinha da Conceição (org.). Gêneros orais no ensino. Campinas, SP: Mercado de Letras, 2015. p. 357-369.

MACHADO, Anna Rachel; LOUSADA, Eliane Gouvêa, ABREU-TARDELLI, Lília Santos. Planejar gêneros acadêmicos. São Paulo: Parábola Editora, 2005.

MARQUES, Oliveira. Como conquistar falando: psicologia do auditório hostil. Rio de Janeiro: Ediouro,1980.

MORELLET, André. Sobre a conversação. Tradução de Maria Ermantina Galvão. São Paulo: Martins Fontes, 2002.

NASCIMENTO, Elvira Lopes do. Debate na sala de aula: gênero catalizador para aprendizagens e desenvolvimento. In: BUENO, Luzia; COSTA-HÜBES, Terezinha da Conceição (org.). Gêneros orais no ensino. Campinas, SP: Mercado de Letras, 2015. p. 197-228.

PLUTARCO. Como ouvir. Tradução de João Carlos Cabral Mendonça. São Paulo: Martins Fontes, 2003.

POLITO, Reinaldo. Como falar corretamente e sem inibições. São Paulo: Editora Saraiva, 1998.

SÃO PAULO (Estado). Secretaria da Educação. Currículo do Estado de São Paulo: linguagens, códigos e suas tecnologias. 2. ed. São Paulo: Secretaria da Educação, 2012. 
SCHNEUWLY, Bernard. Palavra e ficcionalização: um caminho para o ensino da linguagem oral. In: SCHNEUWLY, Bernard; DOLZ, Joaquim. Gêneros orais e escritos na escola. Tradução e organização de Roxane Rojo e Glaís Sales Cordeiro. Campinas, SP: Mercado de Letras, 2004. p. 109-124.

SCHNEUWLY, Bernard; DOLZ, Joaquim. Gêneros orais e escritos na escola. Tradução e organização Roxane Rojo e Glaís Sales Cordeiro. Campinas, SP: Mercado de Letras, 2004.

SCHOPENHAUER, Arthur. Como vencer um debate sem precisar ter razão. Rio de Janeiro: Topbooks, 2003.

SOUZA, Kiara Arantes de; CRISTOVÃO, Vera Lúcia Lopes. O gênero textual "entrevista de emprego": suas características na esfera acadêmica visando a escolas de idiomas. In: BUENO, Luzia; COSTA-HÜBES, Terezinha da Conceição (org.). Gêneros orais no ensino. Campinas, SP: Mercado de Letras, 2015. p. 229276.

UNIVERSIDADE ESTADUAL DE CAMPINAS. Pró Reitoria de Pós-Graduação. Normas para elaboração de teses/dissertação: informação CCPG No 002/2018. Campinas: UNICAMPI, 2018. Disponível em:

https://www2.prpg.unicamp.br/prpg/?page_id=741. Acesso em: 28 mar. 2019.

UNIVERSIDADE DE SÃO PAULO. Sistema Integrado de Bibliotecas. Diretrizes para apresentação de dissertações e teses da USP: nova edição São Paulo: USP, 2016. Disponível em: http://www.sibi.usp.br/noticias/edicao-diretrizes-apresentacaodissertacoes-teses-usp-2016/. Acesso em: 20 jan. 2018. 